Archives de sciences sociales des religions

149 | janvier-mars 2010

Varia

\title{
Hommage à Doris
}

\section{Régine Azria}

\section{OpenEdition}

Journals

Édition électronique

URL : http://journals.openedition.org/assr/21997

DOI : 10.4000/assr.21997

ISSN : 1777-5825

Éditeur

Éditions de l'EHESS

Édition imprimée

Date de publication : 31 mars 2010

Pagination : 285-286

ISBN : 978-2-7132-2253-5

ISSN : 0335-5985

Référence électronique

Régine Azria, "Hommage à Doris », Archives de sciences sociales des religions [En ligne], 149 | janviermars 2010, mis en ligne le 08 juin 2010, consulté le 21 septembre 2020. URL : http:// journals.openedition.org/assr/21997; DOI : https://doi.org/10.4000/assr.21997

() Archives de sciences sociales des religions 


\section{Régine Azria}

\section{Hommage à Doris}

Pionnière, Doris Bensimon ne s'est pas contentée de l'être dans le domaine de la sociologie des "Judaïcités contemporaines » dont elle a inauguré l'étude au CNRS dans le cadre du Groupe de Sociologie des Religions. Elle l'a été sur bien d'autres fronts sociologiques en ouvrant des chantiers jusque-là non encore ou peu explorés. Ce caractère pionnier que devaient présenter certains de ses travaux aux yeux d'une communauté scientifique accaparée par d'autres terrains, apparaît rétrospectivement. Ainsi, l'introduction du judaïsme dans le champ de la sociologie de la religion ouvrait une brèche au sein d'une discipline jusque-là quasi-exclusivement vouée, en France tout au moins, à l'étude du catholicisme. Si le passage de la sociologie religieuse à la sociologie de la religion avait pu être perçu, sorte de victoire laïque, comme un premier bouleversement, la création d'une équipe exclusivement dédiée à l'étude des juifs marquait une autre avancée, de nature différente. Ajoutée aux travaux sur le protestantisme qui faisaient eux aussi leur entrée, elle obligeait à modifier l'intitulé du Laboratoire : le Groupe de sociologie de LA religion devenait dès lors le Groupe de sociologie DES religions. Ce qui, symboliquement et concrètement, n'était pas anodin. Sans doute est-il difficile pour les jeunes chercheurs d'aujourd'hui de mesurer le sens et l'impact d'un tel renoncement au singulier !

Délibérément ou non, je ne saurais le dire, n'ayant pas eu l'occasion d'en parler avec elle, les thèmes qui ont prioritairement retenu l'attention de Doris ont souvent porté sur des sujets qu'on serait tenté de qualifier de "sensibles ". À commencer par sa thèse sur la question féminine (L'évolution de la femme israélite à Fès, Aix-en-Provence, 1962) avec laquelle elle inaugurait sa carrière de sociologue. Ce fut aussi le cas avec son enquête sur le thème, ô combien sensible, des mariages mixtes menée en collaboration avec Françoise Lautman (Un mariage. Deux traditions : Chrétiens et Juifs, Bruxelles, Éditions de l'Université Libre de Bruxelles, 1977), une recherche qui devait ouvrir la voie à d'autres travaux (cf. le dernier en date, Séverine Mathieu, La transmission du judaïsme dans les couples mixtes, Paris, Éditions de l'Atelier, 2009). Ce fut encore le cas pour son enquête, modeste mais pionnière, auprès des anciens élèves des écoles juives (Follow-up des anciens élèves des écoles juives à plein-temps. Rapport d'enquête, Paris, CNRS, 1971, 123 p. ronéotées). On sait à quel point la question scolaire, en général, et celle des écoles confessionnelles, juives en particulier, font 
l'objet d'une attention soutenue dans les milieux juifs (cf. Erik Cohen, L'Étude et l'éducation juive en France ou l'avenir d'une communauté, Paris, Éditions du CNRS, 1991), une attention redoublée ces dernières années, notamment depuis les montées de violence constatées en milieux scolaires et les incidents à caractère antisémites qui y ont été dénoncés, provoquant une ruée vers les écoles privées, juives et non juives.

Un autre de ses chantiers, confirmation de son positionnement à l'écart du mainstream sociologique de son époque, a été son intérêt sur la longue durée pour les juifs d'Afrique du nord. Peu de chercheurs en France, hormis Haïm Zafrani et Claude Tapia, s'intéressaient à ces questions alors. Elle a d'abord retracé leur évolution sur place (L'évolution du judaïsme marocain sous le protectorat français : 1912-1956. Paris - La Haye, Mouton, 1968), puis, d'ouvrages en articles, elle a suivi leurs itinéraires d'intégration tant en France qu'en Israël, avant de recueillir, enfin, récits et témoignages (en collaboration avec Joëlle Allouche-Benayoun avec laquelle elle a publié deux ouvrages).

Enfin, parmi ses autres centres d'intérêts, c'est très certainement son enquête, menée en collaboration avec Sergio Della Pergola, sur La population juive de France : socio-démographie et identité (Jérusalem-Paris, 1984) qui a le plus contribué à la faire connaître. C'est en tout cas celle qui a mobilisé le plus de temps et de moyens et qui demeure une référence inégalée.

Avec cette enquête Doris Bensimon a également été pionnière... et aventurière en osant se confronter, secondée d'une solide équipe, à ce monstre intimidant et énorme qu'était alors l'ordinateur. C'était, ne l'oublions pas, avant la microinformatique et internet. Le maniement de cette technologie n'était ni simple ni léger et nécessitait des opérations longues et fastidieuses. Sa capacité d'adaptation aux technologies modernes à l'heure de la révolution informatique allait de pair avec sa capacité à user d'une palette méthodologique large, adaptée à ses terrains d'enquête : enquête statistique par questionnaires et recours à l'informatique pour la démographie, entretiens ciselés pour les enquêtes qualitatives (récits de vie et histoire orale); dépouillement d'archives minutieux et méthodiques pour les enquêtes historiques, ...

Ce serait une omission grave, enfin, de ne pas ajouter que Doris la sociologue se doublait d'une Doris militante. L'une et l'autre étaient animées par une même flamme ardente : celle de la laïcité et de l'amour d'Israël. Quant aux autres facettes de cette femme aux vies multiples, elles appartiennent au domaine de l'intime bien qu'elle ait souhaité s'en expliquer dans une autobiographie récente (Quotidien du vingtième siècle. Histoire d'une vie mouvementée, Paris, L'Harmattan, 2007).

L'image que je retiens de Doris est son regard, noir, intense, chaleureux, enveloppant : celui d'une femme de conviction, juive et laïque, tenace et courageuse, fidèle à ses engagements... jusqu'au bout. Un Mensch, en somme. 